\title{
Tumor quantification of several fluoropyrimidines resistance gene expression with a unique quantitative RT-PCR method. Implications for pretherapeutic determination of tumor resistance phenotype
}

Barbado Maud $^{1}$, Preisser Laurence ${ }^{1}$, Boisdron-Celle Michele ${ }^{1}$, Verriele Veronique ${ }^{2}$, Lorimier Gerard ${ }^{3}$, Gamelin Erick ${ }^{1}$, Morel Alain ${ }^{1 *}$

${ }^{1}$ Cytokines : structure, signalisation et prolifération tumorale INSERM : U564, Université d'Angers, Centre Hospitalier Universitaire 4, Rue Larrey 49933 ANGERS CEDEX 9,FR

2 Laboratoire d'Anatomopathologie Centre régional de lutte contre le cancer, Centre Paul Papin 2, rue Moll 49000 Angers, FR

3 Departement de Chirurgie Oncologique CRLCC Paul Papin, 2, rue Moll 49000 Angers, FR

* Correspondence should be adressed to: Alain Morel <a.morel@unimedia.fr>

\begin{abstract}
Pretherapeutic determination of tumor resistance to chemotherapy is a main challenge, hindered by the low number of mechanisms characterized at the same time, the small size of the clinical specimens and the heterogeneity of the techniques or the lack of true quantification. The aim of the present study was to determine in real time quantitative RT-PCR, tumor cell expression of several transcripts involved in cancer cell resistance with a unique cDNA sample from a tumor biopsy. The technique had to be suitable in clinical practice for determination of several factors involved in resistance to a given drug family, for example, fluoropyrimidines resistance factors: thymidylate synthase (TS), dihydropyrimidine dehydrogenase (DPD), thymidine kinase (TK), dihydrofolate reductase (DHFR), folylpolyglutamate synthetase (FPGS). A frame-shifted artificial construct was designed specifically to work within the same conditions. We validated our technique by quantifying expressions of these 5 genes starting from tissue samples of colorectal carcinoma and the surrounding normal mucosa of 33 different patients. That real time quantitative RT-PCR technique using the frame-shifted artificial construct as a standard provided a real comparison and quantification of different resistance factors. Tumor resistance phenotype determination based on that approach will be investigated in a control study.
\end{abstract}

MESH Keywords Antimetabolites, Antineoplastic ; pharmacology ; Biopsy ; Carcinoma ; metabolism ; Colorectal Neoplasms ; metabolism ; DNA Primers ; chemistry ; DNA, Complementary ; metabolism ; Drug Resistance, Neoplasm ; Fluorouracil ; pharmacology ; Gene Expression Regulation, Neoplastic ; Humans ; Intestinal Mucosa ; metabolism ; Oligonucleotide Array Sequence Analysis ; Phenotype ; Pyrimidines ; pharmacology ; Reverse Transcriptase Polymerase Chain Reaction ; methods

\section{INTRODUCTION}

5-fluorouracil (5-FU)-based chemotherapy is the reference treatment in advanced tumors, especially digestive location. Other drugs, such as CPT-11 or oxaliplatin, can also be used alone or combinated to 5-FU, but the development of tumor cell drug resistance remains a major obstacle to chemotherapy efficiency. Even if drug efficacy has improved mainly through drugs combination [1-3], at least about 50 $\%$ of patients undergo 2 to 3 months of treatment and sometimes severe adverse side effects before a negative response rate assessment Characterization and then quantification of the biochemical determinants to drug response before treatment could be a useful approach to improve therapy results and avoid toxic and useless treatments.

Despite several studies, little is known about factors and parameters involved in tumor cell resistance or sensitivity to 5-FU. Many resistance factors to drugs have been previously described, mainly in vitro but also in vivo and some have been associated with poor outcome and/or response to treatment in preclinical studies [4-8]. Obviously, determination of a single factor is not sufficient to predict therapeutic response. However, some difficulties remain to determine the true implication of different factors in drug resistance. For a long time, most of the studies explored only one isolated resistance factor, such as thymidylate synthase (TS), the 5-FU main target [9-13], and left aside other potential factors, ignoring or at least probably underestimating their respective importance and intrication. Used techniques such as radioenzymatic assay, immunohistochemistry, or semi quantitative RT-PCR, are very different and not easily reproducible and standardized. These methods have shown shortcomings in term of sensitivity, specificity or applicability in clinical practice: radioenzymatic assay is tedious, time consuming and needs radioisotopes; immunohistochemistry is not truly quantitative and semiquantitative RT-PCR is laborious. Finally this analytical heterogeneity prevents the understanding of the respective predictive value of the suspected drug resistance factors in clinical practice so far.

More and more studies confirm that simultaneous quantification of several markers would permit to improve their prediction value in outcome or response to chemotherapy [14-19].

The technique of real time quantitative RT-PCR appears to be an interesting approach, with a higher sensitivity than conventional methods, and a better feasibility than enzymatic techniques with small tissue samples. Actually, it allows quantifying multiple mRNAs 
expression with a very low amount of material. But real time RT-PCR quantification depends firstly on the accurate quantification of the used DNA standard [20]. Multiple standard molecules are classically needed when determining the expression of several genes, and this could generate some variability due to the quantification of individual DNA standard, by either spectrophotometry or fluorescence or due to the quality of the DNA preparation itself. According to those observations, our purpose in the present study was to set up a single, simple and accurate quantitative PCR method for quantifying several resistance determinants under common amplification characteristics. This method could be a promising innovative alternative approach to achieve a real prediction of response to chemotherapy before starting a treatment.

We developed one composite standard DNA molecule for quantification of several mRNA in order to make sure we obtained accurate relative quantification of all the genes expressions. Primers sets for each studied mRNA were selected before composite standard DNA construction. Couple of primers had to work under the same PCR conditions, generate PCR products of almost the same length, and produce no amplification artefacts.

We chose to elaborate a composite standard DNA molecule for 5-FU resistance factors. This drug and oral fluoropyrimidines are widely used in treatment of numerous cancer types, especially gastrointestinal cancer but also breast and head and neck cancers, and represent almost $50 \%$ of the chemotherapy prescription. We focused on transcripts expression of 5 genes, which are most often reported in tumor resistance to 5-FU: TS is the key enzyme of thymidine de novo synthesis and the main cellular target of 5-FU; Dihydropyrimidine dehydrogenase (DPD) is the initial and rate-limiting enzyme for 5-FU catabolism and leads to dihydrofluorouracil; Thymidine kinase (TK) catalyses the phosphorylation of deoxythymidine in the salvage pathway of dTMP synthesis; Dihydrofolate reductase (DHFR) is the key enzyme of folates cycle, reducing folates in dihydrofolate (DHF) and tetrahydrofolate (THF) in the cell; and the folylpolyglutamate synthetase (FPGS) is responsible for folate polyglutamylation.

We validated the protocol by evaluation of these 5 genes in tissue biopsies of colorectal carcinoma and the surrounding mucosa from 33 patients who underwent surgery for colorectal cancer.

\section{MATERIALS AND METHODS}

\section{Primer design}

Most of primers used in this study were designed by using primer3 freeware (http:/Aveb.umassmed.edu/bioapps/primer3_www.cgi) and obtained desalted from Invitrogen. All primers had to work under the same conditions: annealing temperature of $55^{\circ} \mathrm{C}, \mathrm{MgCl}_{2}$ final concentration of $4 \mathrm{mM}$ and PCR product sizes not exceeding $500 \mathrm{bp}$ (primers characteristics are depicted in Table I).

Each pair of primers was tested by capillary PCR (Lightcycler, Roche Diagnostics) using "Lightcycler FastStart DNA Master SYBR green I" (Roche Diagnostics). The absence of amplification artefacts was confirmed by establishing a melting curve at the end of amplification and by gel electrophoresis analysis (Figure 1). Moreover, PCR product of each set of primers was cloned into pGEM-T easy vector (Promega) and sequenced (CEQ 2000 apparatus, Beckman Coulter Standard).

\section{Composite standard DNA construction}

As described in Figure 2A, addition of primer sequence was done by PCR using overlapping primers, and the first overlapping primer was added by PCR on a stuffer DNA corresponding to a 259 pb sequence of the Rat V1a receptor (nucleotide 141 to 399) [21].

First sequence addition was performed in a $50 \mu \mathrm{l}$ volume with $10 \mathrm{ng}$ of cloned Rat V1a receptor cDNA, $1 \mu \mathrm{M}$ of each overlapping primer, $400 \mu \mathrm{M}$ dNTPs, $2.5 \mathrm{mM} \mathrm{MgCl}{ }_{2}$ in 1 X PCR buffer, overlaid with mineral oil. After a preliminary denaturing step $\left(94{ }^{\circ} \mathrm{C}\right.$ for $2 \mathrm{~min}$ $30 \mathrm{sec}$ ), reaction was initiated by addition of 2.5 units of Taq polymerase (Eurobio). PCR was then performed under the following conditions: $94{ }^{\circ} \mathrm{C}$ for $30 \mathrm{sec}, 55^{\circ} \mathrm{C}$ for $1 \mathrm{~min}$, and $72{ }^{\circ} \mathrm{C}$ for $1 \mathrm{~min} 30 \mathrm{sec}$ for 20 cycles on a Hybaid thermocycler (Coger). The PCR product was analyzed and purified after low melting agarose gel electrophoresis. Then aliquot of the purified PCR product was used for the subsequent sequence addition under the same conditions of PCR and purification. Final PCR product was purified and cloned into pGEM-T easy vector (Promega). Plasmid was extracted by "QIAprep Spin Miniprep Kit" (Qiagen), quantified by spectrophotometry at 260 $\mathrm{nm}$, and sequenced. Using forward and reverse primers selected in the same conditions, we cloned the fragments of human GAPDH and $\beta$ Actin as normalization housekeeping genes.

\section{In-vitro transcription}

Synthetic RNAs for the establishment of standard curves were obtained from $1 \mu \mathrm{g}$ of pGEM-T easy vector (containing composite standard DNA or fragments of GAPDH or $\beta$ Actin) used as template for in-vitro transcription reaction with T7 RNA Polymerase ("RNA Transcription Kit", Stratagene) following the manufacturer's instructions. The obtained standard synthetic RNA were quantified by measuring absorbance at $260 \mathrm{~nm}$. After concentration adjustment, synthetic RNA were aliquoted and stored at $-80^{\circ} \mathrm{C}$.

\section{Human tissue collection}


Pairs of colorectal tumors and the surrounding normal mucosa were obtained from 33 patients who underwent surgery for colon or rectal cancer at the Centre Regional de Lutte Contre le Cancer Paul Papin, Angers, during the period between December 1999 and May 2003. Patients were treated according to the diagnostic of their disease, and could receive or not a treatment containing 5-FU, before and/or after the operation.

All samples were checked by a pathologist before they were frozen and stored in liquid nitrogen until RNA isolation. Patients' characteristics are presented in Table II.

\section{Total RNA extraction}

Frozen tissue fragments were included in Tissue Tek (Sakura), and 10 to 20 slices $30 \mu \mathrm{m}$ thickness were collected using a cryostat at $27^{\circ} \mathrm{C}$. Total RNA was extracted immediately using the "High Pure RNA Tissue Kit" (Roche Diagnostics) following manufacturer's procedure. Anatomopathologic exam of each sample was performed again on one interposed slice to confirm the nature of each specimen. After elution, total RNA was aliquoted and stored at $-70{ }^{\circ} \mathrm{C}$ until use. RNA concentrations could not be determined since tissue samples were too small.

\section{Reverse-transcription}

$10 \mu \mathrm{l}$ of total RNA tissue sample, or known amount of standard synthetic RNA (serial dilution starting from $10^{3}$ to $10^{-2} \mu \mathrm{g} / \mu \mathrm{l}$ synthetic RNA concentration) were mixed with $2.65 \mu \mathrm{g}$ of random hexamers (Amersham Pharmacia Biotech) in $15 \mu \mathrm{l}$ final volume, incubated at 70 ${ }^{\circ} \mathrm{C}$ for $5 \mathrm{~min}$ and chilled on ice. Then the reaction was performed at $37{ }^{\circ} \mathrm{C}$ for 1 hour with $200 \mu \mathrm{M}$ dNTPs, 40 units of RNase Inhibitor (RNasin, Promega) and 200 units of Moloney Murine Leukemia Virus Reverse Transcriptase (MMLV-RT) (Promega) in a $50 \mu 1$ final volume of buffer recommended by supplier. For each sample, a reaction without MMLV-RT was done as negative control. Then cDNA was purified using "Qiaquick PCR Purification Kit" (Qiagen). Purified cDNA was aliquoted and stored at $-20^{\circ} \mathrm{C}$.

\section{Real-time PCR}

Amplification was done in a final volume of $10 \mu \mathrm{l}$ containing $5 \mu \mathrm{l}$ of cDNA diluted at 0.1 in sterile distilled water (sample or standard), $0.5 \mu \mathrm{M}$ of each primer, $4 \mathrm{mM} \mathrm{MgCl}$, and $1 \mu \mathrm{l}$ of "LightCycler FastStart DNA master SYBR green I" 10X (Roche Diagnostics). Then the following protocol was used: (i) denaturation program $\left(95^{\circ} \mathrm{C}\right.$ for $10 \mathrm{~min}$ ), (ii) amplification and quantification program repeated 40 cycles $\left(95{ }^{\circ} \mathrm{C}\right.$ for $15 \mathrm{sec}, 55^{\circ} \mathrm{C}$ for $11 \mathrm{sec}, 72{ }^{\circ} \mathrm{C}$ for $22 \mathrm{sec}$, with a single fluorescence measurement of SYBR green I at each end of cycle), (iii) melting curve program $\left(65-99{ }^{\circ} \mathrm{C}\right.$ with a heating rate of $0.1{ }^{\circ} \mathrm{C}$ and continuous fluorescence measurement). In this study, the Second Derivate Maximum Method was used for Crossing Point (Cp) determination, using LightCycler Software 3.3 (Roche Diagnostics).

GAPDH, TS, TK, FPGS, DHFR and DPD mRNA were quantified starting from 2 independent RT reactions followed by PCR amplification in a one assay-run for each tissue sample.

\section{Statistic al analysis}

Results are presented as mean value +/- standard errors (SD). Statistical analysis was performed using SPSS 10.0 software. Correlations were performed using the Spearman rank test (rs). mRNA levels of the primary colorectal cancer and those of the corresponding normal mucosa were compared using the Wilcoxon signed rank test. Statistical differences between clinicopathological factors were evaluated using non parametric tests, Mann-Whitney U-test between 2 groups and Kruskall-Wallis test for 3 or more groups. A p value less than 0.05 was considered to be statistically significant.

\section{RESULTS}

\section{Selection of PCR primer sets}

Preliminary studies focused on the design of optimized primers working with good and highly comparable amplification efficiency in the standard conditions of PCR we choose SYBR green I, annealing temperature of $55{ }^{\circ} \mathrm{C}$ and $\mathrm{MgCl}_{2}$ final concentration of $4 \mathrm{mM}$ for the 5 genes of interest. Different couples of reverse and forward oligonucleotides for TS, DPD, TK, FPGS, DHFR and housekeeping genes GAPDH and $\beta$ Actin were tested using cDNA prepared from total colon tissue RNA or $\mathrm{H}_{2} \mathrm{O}$ as a template, random hexamers and MMLV-RT. Every primer had to present a good amplification curve, a single melting peak showing no artefact amplification, and a single band with the expected size after gel electrophoresis of each PCR product (Figure 1). Sequencing of cloned PCR products confirmed the specificity of amplification. Oligonucleotides sequences and physical characterization of PCR products are depicted in Table I. Since RT-PCR could provide variable quantities of cDNA products depending on the quality of RNA sample and on efficiency of the RT reaction [22], we tested RT-PCR protocol. We got a very good reproducibility of RT reaction as Cp value standard deviation for a single RT reaction was less than 0.2 in triplicate, and for 5 different reverse transcription reactions was less than 0.25 for each gene in a one assay-run PCR (data not shown). 


\section{Construction of the DN A composite standard}

The construction of the DNA composite standard is outlined Figure 2. It consisted of five successive steps of PCR using overlapping primers around a 259 bp sequence from rat V1a receptor (Figure 2A). Each step of construction was checked by gel electrophoresis ( Figure 2B), and the final construct was then cloned into pGEM-T easy vector. The composite standard was designed to produce amplicon size of almost the same length for the 5 primer pairs of interest: 390, 386, 385, 388, and 385 bp for TS, TK, DHFR, DPD and FPGS, respectively (Figures 2C and 2D). The quality of the standard molecule was asserted by sequencing analysis after cloning.

\section{Establishment of standard curves}

Standard synthetic RNA was obtained by in-vitro transcription of the cloned composite standard DNA or cloned fragment of GAPDH. At first, RT-PCR amplification starting from the same concentrations of standard synthetic RNA $\left(10^{3} \mu \mathrm{g} / \mu \mathrm{l}\right)$ was realized with each couple of primers and gave almost the same Cp (19.99 \pm 0.55 cycles) showing a comparable amplification efficiency of each primer set. Then, standard curves were realized for each couple of primers starting from eight increasing synthetic concentrations. Slopes calculated from linear relationship between $\mathrm{Cp}$ and logarithm of the initial synthetic RNA amount varied from -3.99 for DPD to -3.34 for GAPDH and the regression was always higher than 0.99 (Figure 3). We noticed for each regression curve a slope over the 3.32 value for an amplification efficiency of $100 \%$, this could mean that SYBR green I present in the reaction could slightly inhibit the amplification.

\section{Gene expression levels in biopsies}

At first, we evaluated the integrity of total RNA extracted from tissue sample of 35 patients (couple of colorectal carcinoma and the surrounding normal mucosa) by amplification of GAPDH mRNA, after RT-PCR performed with or without MMLV-RT. Quantification was then performed with the tissue samples of the 33 patients since 2 colorectal carcinoma samples presented significant genomic DNA contamination (data not shown).

As the purpose of our study was to truly quantify mRNA whatever the origin and/or the amount of the tissues, we had to normalize each sample in order to obtain an accurate relative quantification for every targeted gene. Quantification of the 2 housekeeping gene GAPDH and $\beta$ Actin mRNA expression showed that they were significantly correlated ( $r s=0,936, p<0.001$ ). We choosed GAPDH because it was more sensitive to genomic contamination [23, 24], and widely used in quantification [14, 15, 25]. Then, relative mRNA levels of TS, TK, FPGS, DHFR and DPD were expressed as the ratio of targeted gene to GAPDH in order to compensate for the variation in RNA amount.

Results showed that even if expression of the 5 studied factors is widely variable, all of them were underexpressed in tumor tissue compared to normal mucosa, slightly for TK and FPGS with $\mathrm{p}<0.05$, and more significantly for TS, DHFR and DPD with $\mathrm{p}<0.005$ (Wilcoxon signed-rank test, Table III).

Several clinicopathological factors, such as Gender, Location, Staging and Differentiation grading were studied. We found some correlation between few clinicopathological factors and mRNA level of every 5 genes in the colorectal carcinomas (Table IV). DPD and FPGS expressions were significantly lower in women as compared to men. DPD mean expression was $26.0 \pm 41.0(\mathrm{n}=16)$ for men and $9.1 \pm 6.3(\mathrm{n}=10)$ for women with $\mathrm{p}=0.023$, and FPGS mean expression was $41.8 \pm 20.0(\mathrm{n}=21)$ for men and $24.4 \pm 8.8(\mathrm{n}=11)$ for women with $\mathrm{p}=0.005$. DHFR expression in tumor tissue was significantly lower for extended disease (group "B" which include metastatic disease and local relapse) when compared to more localized diseases (group "A" which include tumors stages I, II and III) (DHFR mean expression was respectively $40.9 \pm 22.7(\mathrm{n}=11)$ and $62.5 \pm 21.8(\mathrm{n}=22)$ with $\mathrm{p}=0.010)$. TS expression was apparently lower in well differentiated tumors as compared to poorly differentiated specimens (TS mean expression was respectively $31.4 \pm 12.1$ ( $\mathrm{n}=17$ ) and 50.5 $\pm 16.8(\mathrm{n}=4)$ ) but the difference was not stastistically significant $(\mathrm{p}=0.081)$. Conversely, there was no correlation between few clinicopathological factors and mRNA level of every 5 genes in normal mucosa.

We also evaluated correlations between expression of the 5 studied genes in colorectal tumor versus normal mucosa (Table V). Results showed profound differences since mRNA levels of the 5 different genes were generally more correlated between them in the normal mucosa than in the tumoral tissue (TK/DPD, TK/DHFR and FPGS/DPD mRNA levels only remained correlated in the colorectal carcinoma). These observations indicated differences and greater variability of tumoral tissue compared to normal mucosa.

\section{DISCUSSION}

Since drug resistance is frequently at the origin of treatment failure, pretherapeutic characterization of the molecular resistance determinants could be of great interest. It would allow more rational decisions, on whether or not to proceed with 5-FU-based chemotherapy as first line therapy, since other drugs, i.e. CPT-11 and oxaliplatin, are efficient in colorectal cancer in first line therapy. Many independent biological studies described numerous resistance factors, and the expression of some of them correlates with clinical outcome or chemotherapy response. Since these results are hardly comparable, sometimes conflicting and even contradictory, they could not be taken into account in clinical practice until now. Some problems stem from the fact that the used techniques are very different, most 
of them being semi-quantitative, tedious and time consuming, requiring significant amount of tissue, and characterizing only 1 or 2 factors. Quantitative real time PCR is a powerful method for quantifying several transcript expressions from small tissue samples. But it could be sometimes hampered because it depends highly on the accuracy of the quantification of the standard DNA used [24, 26].

The purpose of this study was to overcome these problems by setting up a real time quantitative PCR assay using a unique composite standard DNA molecule to determine transcript expression of resistance factors under the same experimental conditions. It was specifically designed to compensate variations that could occur when quantification of several factors is needed. Moreover, the technique had to be reproducible, feasible starting biopsies-sized tissue samples, easily extended in laboratories and in prospect for large scale studies.

This composite standard was set up to allow the amplification of 5 genes previously reported for their involvement in tumor resistance to 5-FU or in survival. TS, the 5-FU main target, is the most studied gene. Its overexpression is often linked to treatment failure and poor clinical outcome especially in advanced colorectal cancer [12, 15, 27, 28]. DPD is the rate-limiting enzyme of 5-FU, and has been largely studied and reported as a predictor factor. Its underexpression in primary tumor seems to be correlated with an enhanced response to 5-FU and to survival [15, 29]. For the 3 other studied factors, increase of TK [7,19], DHFR [30, 31] or FPGS decrease [17, 32, 33] have also been related to a greater tumor cell resistance to 5-FU, or a worse survival. But these results are often conflicting and large-scale studies necessary for statistical validation and for proving their involvement and importance in practice have been limited.

In order to validate the method, we choose to quantify mRNA expression of the 5 transcripts, in biopsy-sized tissue samples of primary colorectal tumor and normal surrounding mucosa from 33 patients. In many previous studies, the true malignant nature of the tissue and the RNA quality could not be ascertained partly because tissues came from old tumor banks. In the present study, a pathologic exam of the tissue was again performed before RNA extraction to ensure its origin. Unfortunately, It was not possible to control the quality of extracted RNA and to quantify it by standard procedures since it was extracted from very small amount of material. To overcome the inherent variability in human tissue biopsies both in quality and quantity, the quantification was weighted with a control expressed gene, GAPDH. As the use of a housekeeping is necessary, we plan to improve the standard conception by including the primer sequences of this (or those) gene(s). Finally, the RT reaction, which could be limiting due to RNA quality or experimental conditions, was tested and we found that RT-PCR protocol was well reproducible.

Even if the population of interest was heterogeneous it permitted to validate our quantification technology. We observed an underexpression of the 5 studied genes in primary tumor when compared with the normal mucosa. Such difference has already been reported for DPD [34, 35]. There is less data for the other studied genes, and we have no explanation for this observation, except that mucosa is a fast renewing tissue.

Correlations were also observed between several clinicopathological parameters and the expression of the 5 genes.

Decreased FPGS and DPD mRNA expressions were found in women colorectal carcinoma as compared to men tumors whereas this difference was not observed in normal mucosa. Tumors with low DPD expression are considered to be more sensitive to 5-FU. Female gender is often considered as a positive prognostic factor in colorectal cancer, and more recently as a positive factor for 5-FU adjuvant chemotherapy [36]. Such DPD underexpression in women primary tumor has been previously reported [37, 38] and it was proposed that low DPD expression observed in women tumor is problably associated with a better prognostic value for 5-FU chemotherapy.

Results also showed a decreased TS expression in well differentiated colorectal primary tumors. This observation is in agreement with the meaning that low TS expression is of better prognosis for survival, since well differentiated tumor are more aggressive.

Curiously, we also noticed that DHFR mRNA level was underexpressed in colorectal cancer in the case of "B" group which include metastatic diseases and local relapse. Folates present dual modulatory effects on carcinogenesis, but several points in the literature suggest that this observation might be of interest. Indeed, numerous studies suggested that low folate intake increased carcinogenesis [39, 40]. Moreover DHF and methyl-THF had an antiproliferative effect in human colon cancer cell line in vitro [41, 42]. At last, Levy and coll showed that low DHFR mRNA expression correlated significantly with poor outcome in acute lymphocytic leukaemia [43]. It could mean that decrease of DHFR expression might reproduce cellular conditions close to low folate intake, conditions related to carcinogenesis and may be to the severity of the tumoral disease.

Another question was the eventual correlation between gene expressions, because quantification of several genes that are correlated, perhaps co-regulated, would provide no additional benefit for response prediction. The use of a unique standard DNA molecule permitted that study. Our results showed that correlation between the 5 genes was quite different in the 2 types of tissues, since gene expressions were widely correlated in normal mucosa and not in primary tumor. Anterior works have also showed that TS/DPD [16, 25], TS/TK [16], TS/FPGS [18] expressions are not correlated in tumor tissues. Those data highlight a profound difference between colorectal tumor tissue and the normal mucosa, and a high heterogeneity in tumor tissue. This could be of interest in a further study of predictive factors of chemoresistance. 
In the present work, we have developed a real-time quantitative RT-PCR tool, with a unique standard DNA and homogenous PCR procedure. The assay we set up is reproducible, it allows comparison of expression levels of several genes in the same time, and is feasible starting from biopsies-sized tissue samples. Moreover, this technique could be easily used in different laboratories. Nevertheless, quantitative PCR technique show some limits if too many factors are involved in tumor resistance mechanisms. Indeed, Thymidine Phosphorylase, Uridine Kinase, Uridine Phosphorylase, or Orotate Phosphoribosyl Transferase are also linked to 5-FU resistance [5, 7, 44, 45]. Under these conditions technique micro array experiments could represent a powerful alternative. Each of the two techniques have different advantages. Since quantitative RT-PCR is sensible and could be realized with small amount of tissue, it could be quite laborious if quantification of numerous genes is needed. Conversely more tissue sample is used in microarray, but it allow more gene to be investigated. The preliminary determination of a gene implication in drug resistance is essential, the real implication of a gene is essential. For this reason, the development of two technical approachs is complementary. In the future, specific microarrays containing few genes could greatly contribute to the prediction of resistance.

\section{Ackowledgements:}

We thank the "Comite Departemental de la Ligue contre le Cancer du Maine et Loire" and the "Universite d'Angers" for their financial support. M.B. is a recipient of predoctoral fellowship from the "Conseil Regional des Pays de Loire" and the "Comite departemental de la Ligue contre le Cancer du Maine et Loire" and L.P. was supported by a posdoctoral fellowship from "La Ligue Nationale Contre le Cancer". We wish to thank Dr Bertrand for his technical expertise, M Morel and Pr O Coqueret for language corrections.

\section{References:}

- 1. Chau I , Cunningham D Adjuvant therapy in colon cancer: current status and future directions. Cancer Treat Rev. 28: 2002; 223- 236

- 2. de Gramont A, Figer A, Seymour M, Homerin M , Hmissi A, Cassidy J , Boni C, Cortes-Funes H, Cervantes A, Freyer G, Papamichael D , Le Bail N , Louvet C, Hendler D , de Braud F, Wilson C, Morvan F , Bonetti A Leucovorin and fluorouracil with or without oxaliplatin as first-line treatment in advanced colorectal cancer. J Clin Oncol. 18: 2000; 2938- 2947

- 3. Douillard JY , Cunningham D, Roth AD , Navarro M , James RD , Karasek P, Jandik P , Iveson T , Carmichael J , Alakl M , Gruia G , Awad L , Rougier P Irinotecan combined with fluorouracil compared with fluorouracil alone as first-line treatment for metastatic colorectal cancer: a multicentre randomised trial. Lancet. 355: 2000; 10411047

- 4. Mader RM, Muller M, Steger GG Resistance to 5-fluorouracil. Gen Pharmacol. 31: 1998; 661- 666

- 5. Mader RM , Sieder AE , Braun J , Rizovski B , Kalipciyan M , Mueller MW , Jakesz R , Rainer H , Steger GG Transcription and activity of 5-fluorouracil converting enzymes in fluoropyrimidine resistance in colon cancer in vitro. Biochem Pharmacol. 54: 1997; 1233- 1242

- 6. Longley DB , Harkin DP , Johnston PG 5-fluorouracil: mechanisms of action and clinical strategies. Nat Rev Cancer. 3: 2003; 330- 338

- 7. Chung YM , Park S , Park JK , Kim Y, Kang Y, Yoo YD Establishment and characterization of 5-fluorouracil-resistant gastric cancer cells. Cancer Lett. 159: 2000; 95101

- 8. Murakami Y, Kazuno H, Emura T, Tsujimoto H, Suzuki N , Fukushima M Different mechanisms of acquired resistance to fluorinated pyrimidines in human colorectal cancer cells. Int J Oncol. 17: 2000; 277- 283

- 9. Edler D , Blomgren H , Allegra CJ , Johnston PG , Lagerstedt U , Magnusson I, Ragnhammar P Immunohistochemical determination of thymidylate synthase in colorectal cancer-methodological studies. Eur J Cancer. 33: 1997; 2278- 2281

- 10. Johnston PG, Lenz HJ , Leichman CG, Danenberg KD, Allegra CJ , Danenberg PV , Leichman L Thymidylate synthase gene and protein expression correlate and are associated with response to 5-fluorouracil in human colorectal and gastric tumors. Cancer Res. 55: 1995; 1407- 1412

- 11. Leichman CG, Lenz HJ , Leichman L, Danenberg K, Baranda J , Groshen S, Boswell W, Metzger R, Tan M , Danenberg PV Quantitation of intratumoral thymidylate synthase expression predicts for disseminated colorectal cancer response and resistance to protracted-infusion fluorouracil and weekly leucovorin. J Clin Oncol. 15: 1997; 3223 $-3229$

- 12. Aschele C, Lonardi S , Monfardini S Thymidylate Synthase expression as a predictor of clinical response to fluoropyrimidine-based chemotherapy in advanced colorectal cancer. Cancer Treat Rev. 28: 2002; 27- 47

- 13. Peters GJ , Backus HH, Freemantle S, van Triest B , Codacci-Pisanelli G, van der Wilt CL, Smid K, Lunec J , Calvert AH , Marsh S , McLeod HL, Bloemena E, Meijer S , Jansen G, van Groeningen CJ , Pinedo HM Induction of thymidylate synthase as a 5-fluorouracil resistance mechanism. Biochim Biophys Acta. 1587: 2002; 194205

- 14. Fujiwara H, Terashima M , Irinoda T , Takagane A, Abe K, Kashiwaba M , Oyama K, Takahashi M , Maesawa C , Saito K , Takechi T , Fukushima M Quantitative measurement of thymidylate synthase and dihydropyrimidine dehydrogenase mRNA level in gastric cancer by real-time RT-PCR. Jpn J Cancer Res. 93: 2002; 1342- 1350

- 15. Ichikawa W, Uetake H, Shirota Y, Yamada H, Nishi N , Nihei Z, Sugihara K, Hirayama R Combination of dihydropyrimidine dehydrogenase and thymidylate synthase gene expressions in primary tumors as predictive parameters for the efficacy of fluoropyrimidine-based chemotherapy for metastatic colorectal cancer. Clin Cancer Res. 9: 2003; 786- 791

- 16. Salonga D , Danenberg KD , Johnson M , Metzger R, Groshen S, Tsao-Wei DD , Lenz HJ , Leichman CG , Leichman L , Diasio RB , Danenberg PV Colorectal tumors responding to 5-fluorouracil have low gene expression levels of dihydropyrimidine dehydrogenase, thymidylate synthase, and thymidine phosphorylase. Clin Cancer Res. 6 : 2000; 1322- 1327

- 17. Cheradame S, Etienne MC, Formento P, Schneider M, Dassonville O, Demard F, Milano G Tumoral-reduced folates and clinical resistance to fluorouracil-based treatment in head and neck cancer patients. J Clin Oncol. 15: 1997; 2604- 2610

- 18. Chazal M , Cheradame S , Formento JL, Francoual M , Formento P, Etienne MC, Francois E, Richelme H , Mousseau M , Letoublon C, Pezet D , Cure H , Seitz JF , Milano G Decreased folylpolyglutamate synthetase activity in tumors resistant to fluorouracil-folinic acid treatment: clinical data. Clin Cancer Res. 3: 1997; $553-557$

- 19. Kralovanszky J , Koves I , Orosz Z, Katona C, Toth K, Rahoty P, Czegledi F, Kovacs T, Budai B , Hullan L, Jeney A Prognostic significance of the thymidylate biosynthetic enzymes in human colorectal tumors. Oncology. 62: 2002; 167- 174

- 20. Jung R , Soondrum K , Neumaier M Quantitative PCR. Clin Chem Lab Med. 38: 2000; 833- 836

- 21. Morel A, O'Carroll AM , Brownstein MJ , Lolait SJ Molecular cloning and expression of a rat V1a arginine vasopressin receptor. Nature. 356 : $1992 ; 523-526$

- 22. Lekanne Deprez RH , Fijnvandraat AC, Ruijter JM , Moorman AF Sensitivity and accuracy of quantitative real-time polymerase chain reaction using SYBR green I depends on cDNA synthesis conditions. Anal Biochem. 307: 2002; 63- 69

- 23. Tso JY, Sun XH, Kao TH , Reece KS , Wu R Isolation and characterization of rat and human glyceraldehyde-3-phosphate dehydrogenase cDNAs: genomic complexity and molecular evolution of the gene. Nucleic Acids Res. 13: 1985; 2485- 2502

- 24. Winer J, Jung CK, Shackel I, Williams PM Development and validation of realtime quantitative reverse transcriptase-polymerase chain reaction for monitoring gene expression in cardiac myocytes in vitro. Anal Biochem. 270: 1999; $41-49$ 
- 25. Yoshinare K, Kubota T, Watanabe M, Wada N , Nishibori H, Hasegawa H, Kitajima M, Takechi T, Fukushima M Gene expression in colorectal cancer and in vitro chemosensitivity to 5-fluorouracil: a study of 88 surgical specimens. Cancer Sci. 94: 2003; 633- 638

- 26. Stoitchkov K, Letellier S, Garnier JP, Toneva M, Naumova E, Peytcheva E, Tzankov N, Bousquet B , Morel P, Le Bricon T Evaluation of standard tyrosinase RT-PCR in melanoma patients by the use of the LightCycler system. Clin Chim Acta. 306: 2001; 133- 138

- 27. Allegra CJ , Parr AL, Wold LE, Mahoney MR, Sargent DJ , Johnston P, Klein P, Behan K, O'Connell MJ , Levitt R , Kugler JW , Tria Tirona M , Goldberg RM Investigation of the prognostic and predictive value of thymidylate synthase, p53, and Ki-67 in patients with locally advanced colon cancer. J Clin Oncol. 20: 2002; $1735-1743$

- 28. Paradise A, Simone G, Petroni S, Leone B , Vallejo C, Lacava J, Romero A, Machiavelli M, De Lena M , Allegra CJ , Johnston PG Thymidilate synthase and p53 primary tumour expression as predictive factors for advanced colorectal cancer patients. Br J Cancer. 82: 2000; 560- 567

- 29. van Kuilenburg AB Dihydropyrimidine dehydrogenase and the efficacy and toxicity of 5-fluorouracil. Eur J Cancer. 40: 2004; 939 - 950

- 30. Spears CP Clinical resistance to antimetabolites. Hematol Oncol Clin North Am. 9: 1995; 397- 413

- 31. Konishi Y, Kanamaru R, Ishioka C, Ishikawa A, Shibata H, Wakui A, Dei T The changes in the levels of dihydrofolate reductase mRNA and its gene dosage in 5-fluorouracil-resistant L1210 cells. Tohoku J Exp Med. 161: 1990; 33- 42

- 32. Wang FS , Aschele C, Sobrero A, Chang YM , Bertino JR Decreased folylpolyglutamate synthetase expression: a novel mechanism of fluorouracil resistance. Cancer Res. 53: 1993; 3677- 3680

- 33. Odin E, Wettergren Y, Nilsson S, Willen R, Carlsson G, Spears CP, Larsson L, Gustavsson B Altered gene expression of folate enzymes in adjacent mucosa is associated with outcome of colorectal cancer patients. Clin Cancer Res. 9: 6012- 6019 2003;

- 34. McLeod HL, Sludden J , Murray GI, Keenan RA, Davidson AI , Park K, Koruth M, Cassidy J Characterization of dihydropyrimidine dehydrogenase in human colorectal tumours. Br J Cancer. 77: 1998; 461- 465

- 35. Ikeguchi M, Hirooka Y, Makino M, Kaibara N Dihydropyrimidine dehydrogenase activity of cancerous and non-cancerous tissues in liver and large intestine. Oncol Rep 8: $2001 ; 621-625$

- 36. Elsaleh H, Joseph D, Rieu GF, Zeps N, Spry N, Iacopetta B Association of tumour site and sex with survival benefit from adjuvant chemotherapy in colorectal cancer. Lancet. 355: 2000; 1745- 1750

- 37. Yamashita K, Mikami Y, Ikeda M, Yamamura M, Kubozoe T, Urakami A, Yoshida K, Kimoto M , Tsunoda T Gender differences in the dihydropyrimidine dehydrogenase expression of colorectal cancers. Cancer Lett. 188: 2002; 231- 236

- 38. Tsuji T, Sawai T, Takeshita H, Nakagoe T, Hidaka S, Atsushi N, Yamaguchi H, Yasutake T, Nagayasu T, Tagawa Y Tumor dihydropyrimidine dehydrogenase in stage II and III colorectal cancer: low level expression is a beneficial marker in oral-adjuvant chemotherapy, but is also a predictor for poor prognosis in patients treated with curative surgery alone. Cancer Lett. 204: 2004; 97- 104

- 39. Choi SW , Mason JB Folate status: effects on pathways of colorectal carcinogenesis. J Nutr. 132: 2002; 2413S- 2418S

- 40. Kim YI Folate, colorectal carcinogenesis, and DNA methylation: lessons from animal studies. Environ Mol Mutagen. 44: 2004; 10- 25

- 41. Akoglu B , Faust D , Milovic V, Stein J Folate and chemoprevention of colorectal cancer: Is 5-methyl-tetrahydrofolate an active antiproliferative agent in folate-treated colon-cancer cells?. Nutrition. 17: 2001; 652- 653

- 42. Jaszewski R, Khan A, Sarkar FH, Kucuk O, Tobi M, Zagnoon A, Dhar R, Kinzie J , Majumdar AP Folic acid inhibition of EGFR-mediated proliferation in human colon cancer cell lines. Am J Physiol. 277: 1999; C1142- 1148

- 43. Levy AS, Sather HN, Steinherz PG, Sowers R, La M, Moscow JA, Gaynon PS , Uckun FM, Bertino JR, Gorlick R Reduced folate carrier and dihydrofolate reductase egression in acute lymphocytic leukemia may predict outcome: a Children's Cancer Group Study. J Pediatr Hematol Oncol. 25: 2003; 688- 695

- 44. Boyer J , McLean EG, Aroori S, Wilson P, McCulla A, Carey PD, Longley DB , Johnston PG Characterization of p53 wild-type and null isogenic colorectal cancer cell lines resistant to 5-fluorouracil, oxaliplatm, and irinotecan. Clin Cancer Res. 10: 2004; 2158- 2167

- 45. Isshi K, Sakuyama T, Gen T, Nakamura Y, Kuroda T, Katuyama T, Maekawa Y Predicting 5-FU sensitivity using human colorectal cancer specimens: comparison of tumor dihydropyrimidine dehydrogenase and orotate phosphoribosyl transferase activities with in vitro chemosensitivity to 5-FU. Int J Clin Oncol. 7: 2002; 335- 342 


\section{Figure 1}

Amplification curve, melting peak and gel analysis of the 5 studied genes DPD, TS, TK, DHFR, and FPGS after RT-PCR. The five couple of primers were tested using MMLV-Reverse Transcriptase, random hexamers, and cDNA made from total mucosa tissue RNA (RT+) or $\mathrm{H}_{2} \mathrm{O}$ $\left(\mathrm{RT}_{2} \mathrm{O}\right)$ as a template. Selected primers gave a single melting peak and a single band of the expected size after agarose gel electrophoresis.
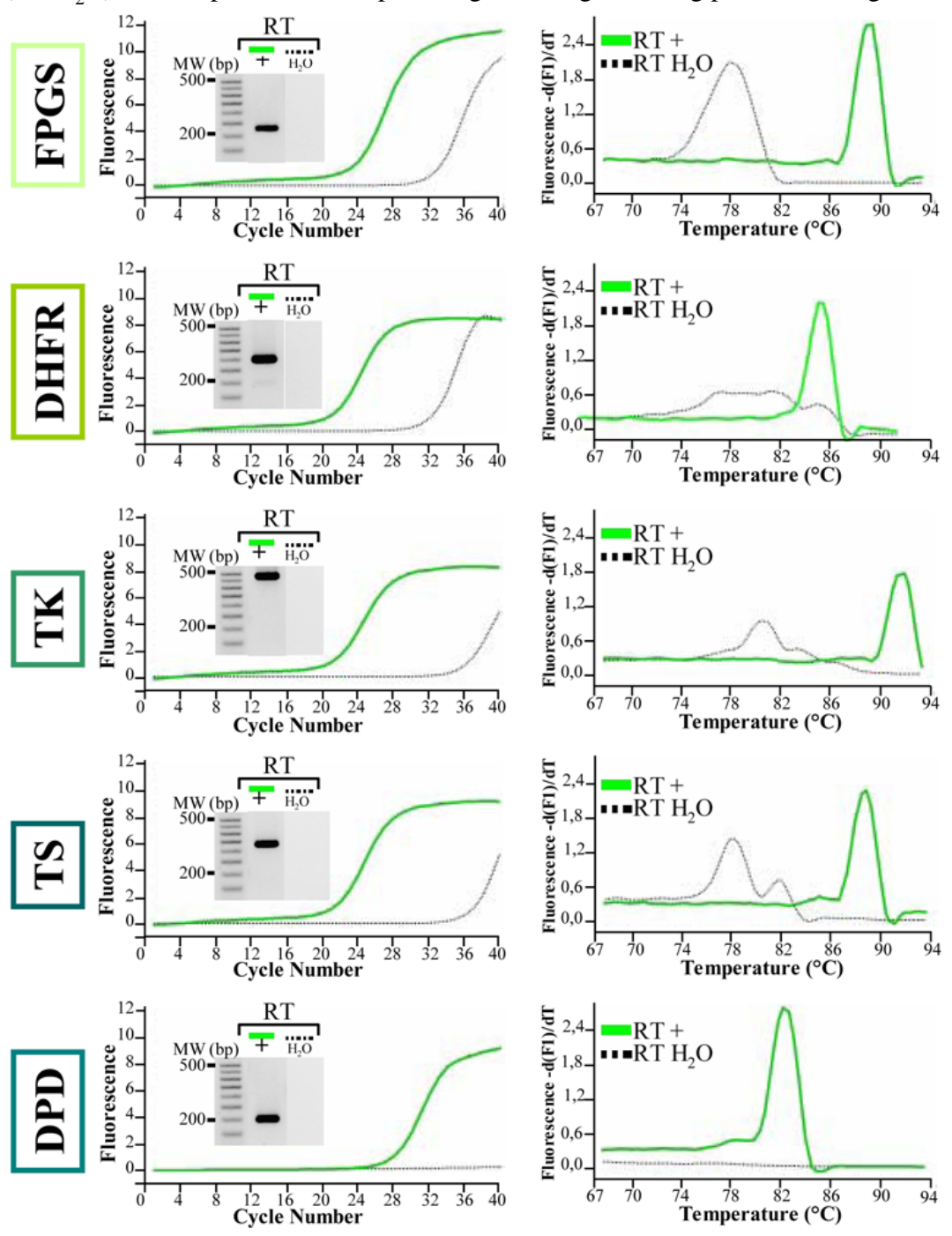

Amplification curve - Gel Analysis

Melting Peak 


\section{Figure 2}

Build-up and amplification of the composite standard DNA. The composite standard DNA was constructed by 5 successive steps of PCR around a 259 bp sequence from the V1a vasopressin Rat receptor using overlapping oligonucleotide primers (A). Each step of primers addition to the construction was checked by gel electrophoresis, and at each step the observed band was used for the next addition of primers sequence (B). After cloning into pGEM-T easy vector the final standard construct was used as a template by PCR in the standard conditions, with every 5 specific primer pairs. Every PCR product had approximately the same length (C, D).

A

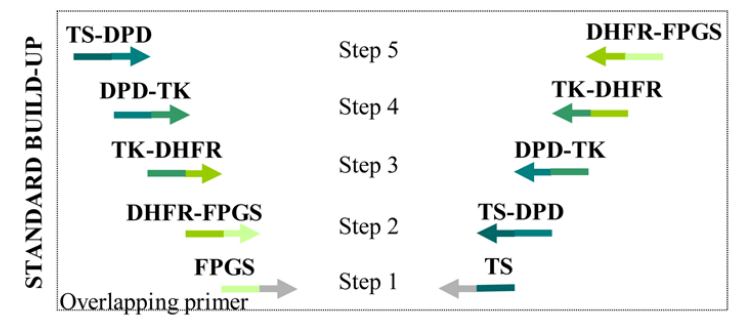

Stuffer DNA (259pb)

C

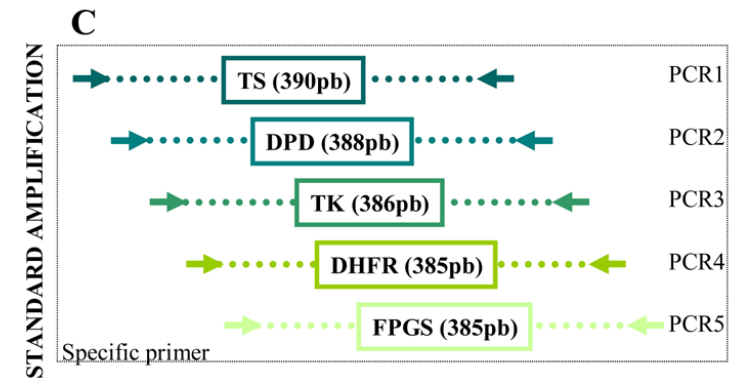

B

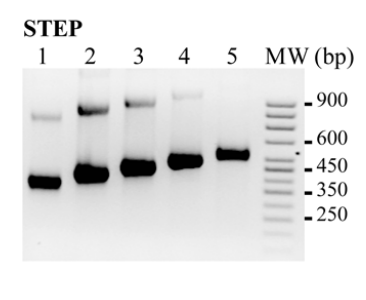

D

PCR

$\begin{array}{cccccc}1 & 2 & 3 & 4 & 5 & \text { MW (bp) }\end{array}$

$\begin{aligned} & \equiv-900\end{aligned}$

$-\infty-\infty \begin{aligned} & -600 \\ & -450 \\ & -350 \\ & -250\end{aligned}$

$-250$

\section{Figure 3}

Linear relationship between $\mathrm{Cp}$ and logarithm of the starting synthetic RNA concentration. The standard curves were generated with eight points (corresponding to initial amount from $10^{3}$ to $10^{-2} \mu \mathrm{g} / \mu \mathrm{l}$ of synthetic RNA), each point represents the mean \pm SD of at least 4 independent experiments.
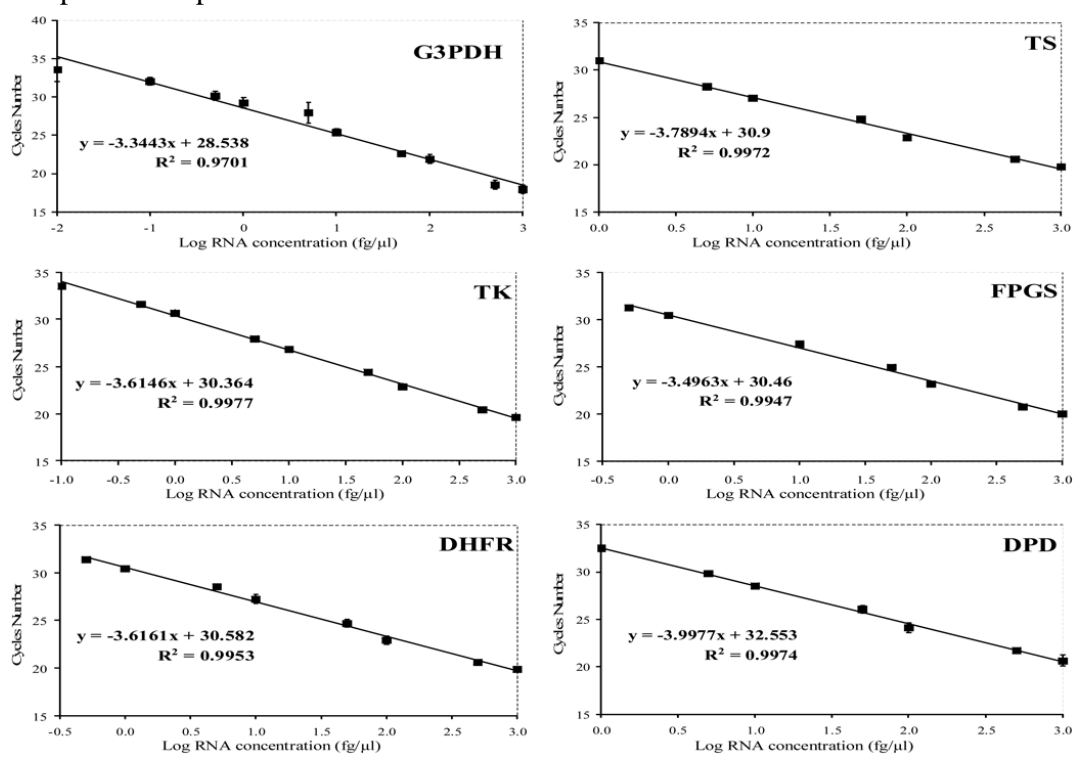
Table I

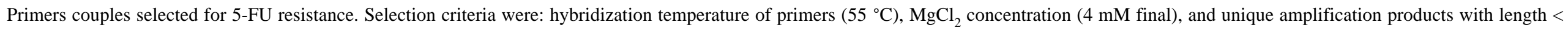

$500 \mathrm{bp}$.

\begin{tabular}{|c|c|c|c|c|c|}
\hline 5-FU Resistance Factors & & Sequence & Length (bp) & $\operatorname{Tm}\left({ }^{\circ} \mathbf{C}\right)$ & Access number \\
\hline \multirow[t]{2}{*}{ TS } & Up & CATTTTGGGGCAGAATACAGAGAT & 300 & 89 & NM_001071 \\
\hline & Down & GATGTGCGCAATCATGTACGTGAG & & & \\
\hline \multirow[t]{2}{*}{ DPD } & $\mathrm{Up}$ & TCAGAAGAGCTGTCCAACTAAT & 229 & 82.7 & NM_000110 \\
\hline & Down & GAATACCTCAGTAGCAAATTGC & & & \\
\hline \multirow[t]{2}{*}{ TK } & Up & AAAGCACAGAGTTGATGAGAC & 475 & 91.7 & NM_00358 \\
\hline & Down & AAGTAGCAGAGCCGACACAC & & & \\
\hline \multirow[t]{2}{*}{ DHFR } & $\mathrm{Up}$ & AGTCAGCGAGCAGGTTCTCA & 321 & 86.7 & NM_000791 \\
\hline & Down & GCAGTAAGCCGAGGTCACAC & & & \\
\hline \multirow[t]{2}{*}{ FPGS } & Up & GTCTTCCTCCAAGAGAAGGT & 203 & 88.8 & NM_004957 \\
\hline & Down & GACACCTTGCTTAAAGATGC & & & \\
\hline \multirow[t]{2}{*}{$\beta$-Actin } & Up & TCAGAAGGATTCCTATGTGG & 236 & 90 & AF261085 \\
\hline & Down & AGGTCTCAAACATGATCTGG & & & \\
\hline \multirow[t]{2}{*}{ GA3PDH } & $\mathrm{Up}$ & GAAGGTGAAGGTCGGAGTC & 226 & 85 & XM_004814 \\
\hline & Down & GAAGATGGTGATGGGATTTC & & & \\
\hline
\end{tabular}

\section{Table II}

Clinical characteristics of the patients

\section{Variables}

Total

Sex

Age (year)

Primary tumor site

Stage

Histology

No. of patients

$\begin{array}{lc}\text { Male } & 33 \\ \text { Female } & 22 \\ \text { Median } & 11 \\ \text { Range } & 69 \\ \text { Left colon } & 49-84 \\ \text { Right colon } & 9 \\ \text { Rectum } & 8 \\ \text { I } & 16 \\ \text { II } & 5 \\ \text { III } & 5 \\ \text { IV } & 9 \\ \text { Local relapse } & 10 \\ \text { Well differentiated } & 4 \\ \text { Moderately differentiated } & 18 \\ \text { Poorly or undifferentiated } & 11\end{array}$


Table III

Comparison of mRNA expression levels of TS, TK, FPGS, DHFR, and DPD between the primary colorectal cancer and the corresponding normal mucosa (Wilcoxon signed rank test).

\begin{tabular}{|c|c|c|c|c|c|}
\hline & TS & TK & FPGS & DHFR & DPD \\
\hline \multicolumn{6}{|c|}{ Colorectal tumor } \\
\hline Mean \pm SD & $34.7 \pm 15.3$ & $25.9 \pm 10.5$ & $35.7 \pm 18.8$ & $54.8 \pm 24.1$ & $19.5 \pm 33.1$ \\
\hline Range & $14.0-68.4$ & $8.4-53.1$ & $7.3-91.8$ & $18.7-98.0$ & $2.7-175.7$ \\
\hline \multicolumn{6}{|c|}{ Normal mucosa } \\
\hline Mean \pm SD & $56.6 \pm 22.3$ & $32.8 \pm 16.46$ & $51.3 \pm 35.2$ & $78.3 \pm 26.5$ & $47.6 \pm 72.9$ \\
\hline Range & $12.7-131.8$ & $0.0-80.8$ & $23.6-226.4$ & $0.0-138.7$ & $12.1-418.1$ \\
\hline P (Wilcoxon) & $<0.0001$ & 0.021 & 0.017 & 0.002 & 0.001 \\
\hline
\end{tabular}


Table IV

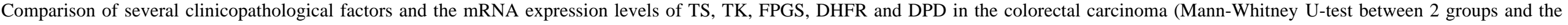
Kruskall-Wallis test for 3 or more groups.

\begin{tabular}{|c|c|c|c|c|c|}
\hline & TS & TK & FPGS & DHFR & DPD \\
\hline & Mean \pm SD (n) & Mean \pm SD (n) & Mean \pm SD (n) & Mean \pm SD (n) & Mean \pm SD (n) \\
\hline \multicolumn{6}{|c|}{ Disease extent } \\
\hline “A” & $36.6 \pm 16.1(20)$ & $26.6 \pm 11.7(20)$ & $33.4 \pm 15.8(20)$ & $62.5 \pm 21.8(20)$ & $12.4 \pm 8.9$ (17) \\
\hline "B" & $31.7 \pm 14.2(12)$ & $24.9 \pm 8.6(12)$ & $39.6 \pm 23.3(12)$ & $40.9 \pm 22.7(11)$ & $32.9 \pm 54.4(9)$ \\
\hline$P$ value & 0276 & 0.938 & $\mathbf{0 . 5 3 3}$ & 0.010 & 0.247 \\
\hline
\end{tabular}

\section{Histological Type}

Well

$$
\begin{gathered}
31.4 \pm 12.1(17) \\
34.2 \pm 17.2(11) \\
50.5 \pm 16.8(4)
\end{gathered}
$$

0210

$\begin{array}{cc}26.9 \pm 12.5(17) & 38.1 \pm 18(17) \\ 23.2 \pm 7.6(11) & 32.1 \pm 22.5(11) \\ 29.6 \pm 8.3(4) & 35.8 \pm 13.3(4) \\ \mathbf{0 . 6 1 9} & \mathbf{0 3 4 5}\end{array}$

$\begin{aligned} 58.3 & \pm 23.5(18) \\ 49 & \pm 24.7(9) \\ 52.4 & \pm 29.9(4) \\ & \mathbf{0 5 0 9}\end{aligned}$

$14.9 \pm 9.8(13)$

\section{Poorly}

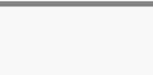

\section{Localisation}

Right colon

Left colon
$35.2+14$ (9)
$30.4 \pm 11.8$ (16)
0420

$27.4 \pm 11.4$ (7)

$25.0 \pm 13.6$ (9)

$25.9 \pm 8.7$ (16)

\section{Rectum}

0.907
$34.2 \pm 19.9(7)$
$37.6 \pm 17.9$ (9)
$35.4 \pm 20.0$ (16)

$P$ value

0.889
$57.5 \pm 23.7(7)$
$54.2 \pm 28.9$ (9)
$54.0 \pm 23.1$ (15)

0541

$12.0 \pm 9.5(9)$

\begin{tabular}{|c|c|c|c|c|c|}
\hline \multicolumn{6}{|l|}{$\underline{\text { Sex }}$} \\
\hline Male & $32.2 \pm 12.8(21)$ & $27.5 \pm 11.0$ & $41.8 \pm 20.0(21)$ & $58.2 \pm 25.7$ & $26.0 \pm 41.0$ \\
\hline Female & $39.5 \pm 19.1(11)$ & $23 \pm 9.2(11)$ & $24.2 \pm 8.8(11)$ & $47.8 \pm 20(10)$ & $9.1 \pm 6.3(10)$ \\
\hline$P$ value & 0226 & 0.258 & 0.005 & 0291 & 0.023 \\
\hline \multicolumn{6}{|l|}{$\underline{\text { Stage }}$} \\
\hline I & $38.8 \pm 19.4(5)$ & $28.4 \pm 11.2(5)$ & $44.3 \pm 16.5(5)$ & $59.1 \pm 9.9$ & $12.9 \pm 6.7$ \\
\hline II & $38.6 \pm 15.2(5)$ & $22.5 \pm 10.1$ & $23.9 \pm 4.4(5)$ & $57.6 \pm 26.7$ & $9.2 \pm 8.0(5)$ \\
\hline III & $35.3 \pm 17.1(9)$ & $27.6 \pm 14.0(9)$ & $33.2 \pm 17.7$ (9) & $68.3 \pm 25.5(9)$ & $14.2 \pm 11.1$ \\
\hline IV & $31.7 \pm 16.3(9)$ & $26.9 \pm 7.9(9)$ & $38.3 \pm 23.6(9)$ & $44.6 \pm 23.7(8)$ & $39.1 \pm 67.1(6)$ \\
\hline$P$ value & 0589 & 0.731 & 0.199 & 0.161 & 0.666 \\
\hline
\end{tabular}

$51.4 \pm 83$ (4)

0.608

A P value less than 0.05 was considered to be statistically significant). Disease extent: "A" include stage I, II and III tumors; "B" include stage IV and local relapse. 
Table V

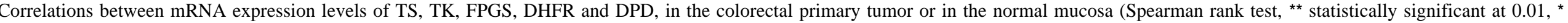
statistically significant at 0.05 )

\begin{tabular}{|c|c|c|c|c|c|c|}
\hline \multirow[b]{2}{*}{ Combination } & \multicolumn{3}{|c|}{ Colorectal tumor } & \multicolumn{3}{|c|}{ Normal mucosa } \\
\hline & Coefficient of correlation & (n) & $P$ value & Coefficient of correlation & (n) & $P$ value \\
\hline TS/DPD & -0.154 & (26) & 0.452 & 0.210 & (32) & 0.248 \\
\hline TS/DHFR & 0.103 & $(30)$ & 0.586 & 0.090 & (30) & 0.638 \\
\hline TS/FPGS & -0.460 & $(32)$ & 0.803 & $0.561^{\star *}$ & (33) & 0.001 \\
\hline TS/TK & 0.085 & (32) & 0.642 & $0.506^{* \star}$ & (33) & 0.003 \\
\hline TK/DPD & $0.543^{\star *}$ & (26) & 0.004 & $0.385^{\star}$ & (32) & 0.029 \\
\hline TK/DHFR & $0.426^{*}$ & $(30)$ & 0.019 & $0.565^{\star *}$ & (30) & 0.001 \\
\hline TK/FPGS & 0.258 & (32) & 0.154 & $0.387^{*}$ & (33) & 0.026 \\
\hline FPGS/DPD & $0.685^{\star \star}$ & (26) & $>0.001$ & $0.609^{* *}$ & (32) & $>0.001$ \\
\hline FPGS/DHFR & 0.245 & (30) & 0.192 & 0.283 & (30) & 0.129 \\
\hline DHFR/DPD & 0.232 & (25) & 0.265 & $0.460^{*}$ & (29) & 0.012 \\
\hline
\end{tabular}

